\title{
Partial monosomy 7 with interstitial deletions in two infants with differing congenital abnormalities
}

\author{
M. d'A. CRAWFURD, I. KESSEL, M. LibERMAN, JANET A. MCKEOWN, \\ P. Y. MANDALIA, AND M.A. C. RIDLER
}

From the Kennedy-Galton Centre, Harperbury Hospital, Radlett, Hertfordshire; and the Departments of Paediatrics, Watford General Hospital, Hertfordshire, and Northwick Park Hospital, Harrow, Middlesex

SUMmaRY Two cases of interstitial deletion of chromosome 7 are presented, one involving the short arm and the other the long arm. The cytogenetic, dermatoglyphic, and clinical findings are compared with previously reported cases of chromosome 7 deletion.

The patient with a short arm deletion differs clinically from the previously reported cases but, in common with at least one previous case, has a low total finger ridge count. His interstitial deletion involving the $7 \mathrm{p} 13 \rightarrow 7 \mathrm{p} 21$ region also differs from $7 \mathrm{p}$ deletions reported in earlier cases.

The patient with a long arm deletion has an interstitial loss of the region between 7q11 and 7q21, corresponding to one of three groups of $7 q$ deletion that have been recognised. The phenotypic changes in this group are less well defined than in the other two and the patient presented here differs clinically from the previously reported cases, apart from one phenotypically normal mosaic case, in lacking morphological abnormalities. He shares with one previous case both epilepsy and a high intensity of dermal ridge patterns.

Complete or partial monosomy 7 occurs, with a greater than chance frequency, in the bone marrow of patients with leukaemia or a myeloproliferative disorder (Rowley and Potter, 1976). In such cases monosomy 7 has been reported as being associated with a lack of Colton blood group antigens (de la Chapelle et al., 1976), and with defective neutrophil chemotaxis to casein (Ruutu et al., 1977).

Monosomy 7 is comparatively rare as a congenital chromosomal anomaly. Zachai and Breg (1973) reported two infants with a ring chromosome 7; Wilson et al. (1973) and Friedrich et al. (1975) have reported infants with a deletion of the terminal dark band of the short arm of chromosome 7. There have been several reports of long arm 7 deletions, most commonly involving a break at band q32 (de Grouchy et al., 1968, 1974; Bass et al., 1973; Harris et al., 1977; Kousseff et al., 1977). Other reported cases of long arm 7 deletion involve loss, secondary to a translocation between chromosome 7 and another chromosome (Shokeir et al., 1973; Turleau et al., 1974; Friedrich et al., 1975, patient 2), or an interstitial deletion of $\mathrm{q} 21$ to $\mathrm{q} 31$ or 32 (Ayraud et al., 1976; Higginson et al., 1976; Franceschini et al., 1978) or of q11 to q21 or 22

Received for publication 6 April 1979
(Valentine and Sergovich, 1977; Seabright and Lewis, 1978, cases 1-3).

We present here two unrelated infants with markedly different phenotypes, both with interstitial deletions of chromosome 7: one of the short arm which differed both cytogenetically and phenotypically from other reported short arms, apart from some dermatoglyphic similarity; and the other of the long arm, associated with a translocation, which also differed phenotypically in several respects from other reported long arm deletion cases. The karyotype-phenotype correlations of partial monosomy 7 are discussed.

\section{Case reports}

CASE 1 (FIG. 1)

A first born child of unrelated parents, a mother of 34 years and father of 35 years, was delivered normally at 38 weeks' gestation. There was a 10-year history of infertility preceding the pregnancy for which both parents had received hormone therapy. The mother had polyhydramnios but radiological and ultrasound investigations in late pregnancy showed no abnormality, and the alphafetoprotein level on amniocentesis was normal. 


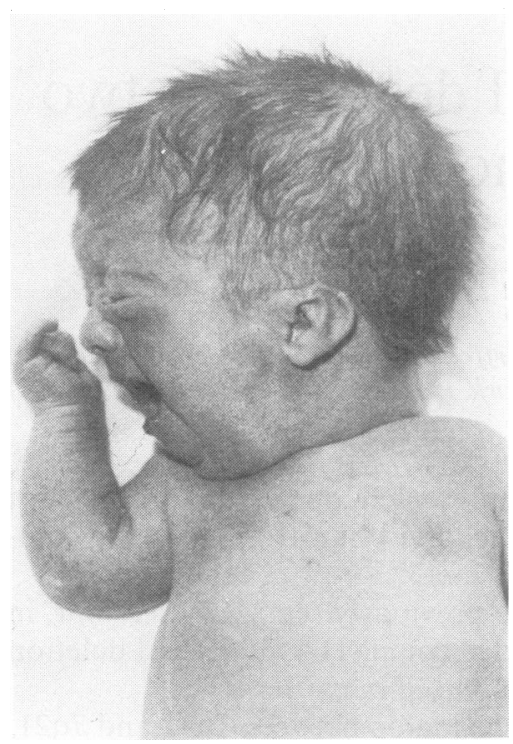

Fig. 1 Clinical photograph of case 1.

The child, a boy, weighed $2500 \mathrm{~g}$ at birth, had a length of $41 \mathrm{~cm}$, and a head circumference of 35.5 $\mathrm{cm}$. On examination he was noted to have a capillary haemangioma in the centre of the forehead; a broad forehead; open anterior, posterior, and third fontanelles with a persistent frontal suture; low set, malformed ears; small eyes and antimongoloid palpebral slant with ptosis of the left upper eye-lid; a small downturned mouth with a long philtrum, a high arched palate, and a receding chin; rhizomelic shortening of both upper and lower limbs, short digits especially thumbs and big toes that are unusually proximally attached, broad wrists with limitation in their range of movement, and talipes equinovarus; a short neck with excess skin folds, a shield chest with widely spaced nipples; small genitalia, glandular hypospadias, and undescended testes. He had a very weak, but not cat-like, cry. He was very slow to feed and initially required repeated tube feeding, was slow to gain weight, and had several brief cyanotic attacks. At 10 weeks his weight was only $3232 \mathrm{~g}$ and on follow-up his development was delayed, fontanelles remained open without any signs of abnormal enlargement of the head, and he had circumoral cyanosis and grunting respiration. No abnormal heart sounds or murmurs have been heard. There is nothing further of significance in the family history. The father has a 46,XY karyotype and the mother $46, \mathrm{XX}$ with a polymorphic variation of a chromosome 3.
CASE 2 (FIG. 2)

The second child of normal unrelated parents a mother of 26 years and a father of 28 years, was delivered spontaneously at 37 weeks' gestation Pregnancy had been uncomplicated but the infant was delivered as an assisted breech. A brother agef $3 \frac{1}{2}$ years was normal.

The child, a boy, weighed $2840 \mathrm{~g}$ at birth and the Apgar score was 10 at one minute. He was slow if feeding with frequent small vomits but gained weighरe satisfactorily. He was said to smile at 7 to 8 week $\vec{s}$ but his subsequent development was slow. At $\underline{\theta}$ months he was seen in a paediatric outpatient clinife after failing a Stycar hearing test. On examinatio then, his head circumference and weight were on the 50th centile. He showed only flitting visuaj attentiveness, was hypotonic, and was unable to sits from the prone position. Both posture and overaft development were assessed as being at the 3 mont 4 level. There were no morphological abnormalities No abnormality was noted on ophthalmoscopy. $\vec{P}$

Urinary amino-acids, organic acids, and muco polysaccharides showed no abnormality. Rubelle्⿱⺈ toxoplasma, and cytomegalovirus serological tes were all normal. All other biochemical investigations gave normal results. Radiological examination of the skull, wrists, and cervical spine showed no skelgtal pathology but the bone age of the hand was on $\frac{1}{3}$ months.

At the time of his first admission at 10 months? was observed to have infantile spasms with jerkin arms, crying, and eye rolling. A history of milï

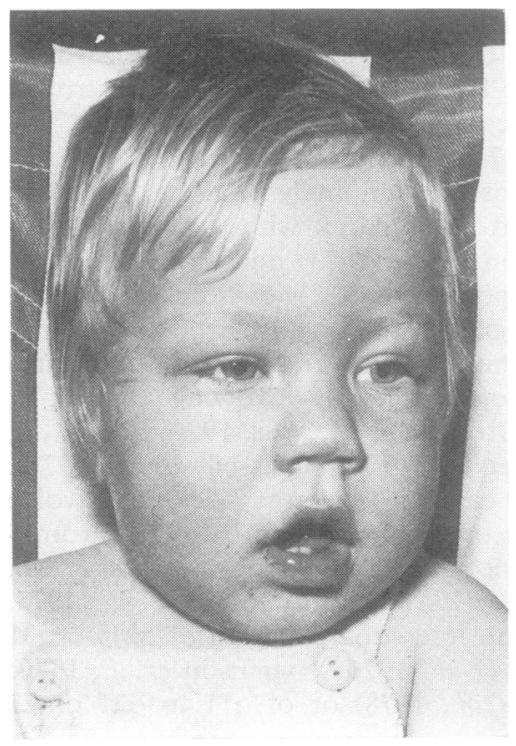

Fig. 2 Clinical photograph of case 2. 
jerking from shortly after birth was obtained. An immediate electroencephalogram gave grossly abnormal patterns in both hemispheres with the emphasis on the left. The pattern resembled hypsarrhythmia with bilateral widespread spikes, sharp waves, and slow waves of 100 to $500 \mu \mathrm{V}$ amplitude. It was somewhat atypical in that the spikes occurred in bursts which remitted at times and there was more asymmetry than would be expected.

He was treated with ACTH and nitrazepam with only temporary response. He has subsequently been managed on several different anticonvulsants but his epilepsy has proved very difficult to control. At $1 \frac{1}{2}$ years he was admitted to hospital for increasing frequency of fits culminating in a convulsion lasting one hour. At the age of $3 \frac{1}{2}$ years, he is severely mentally retarded, chairbound, has some head control, and holds toys in his hands but does not use them in any purposeful way. He makes meaningless sounds, has only very limited attention, but does see and hear.

\section{DERMATOGLYPHIC FINDINGS}

Case 1 (Fig. 3). The dermatoglyphic configurations
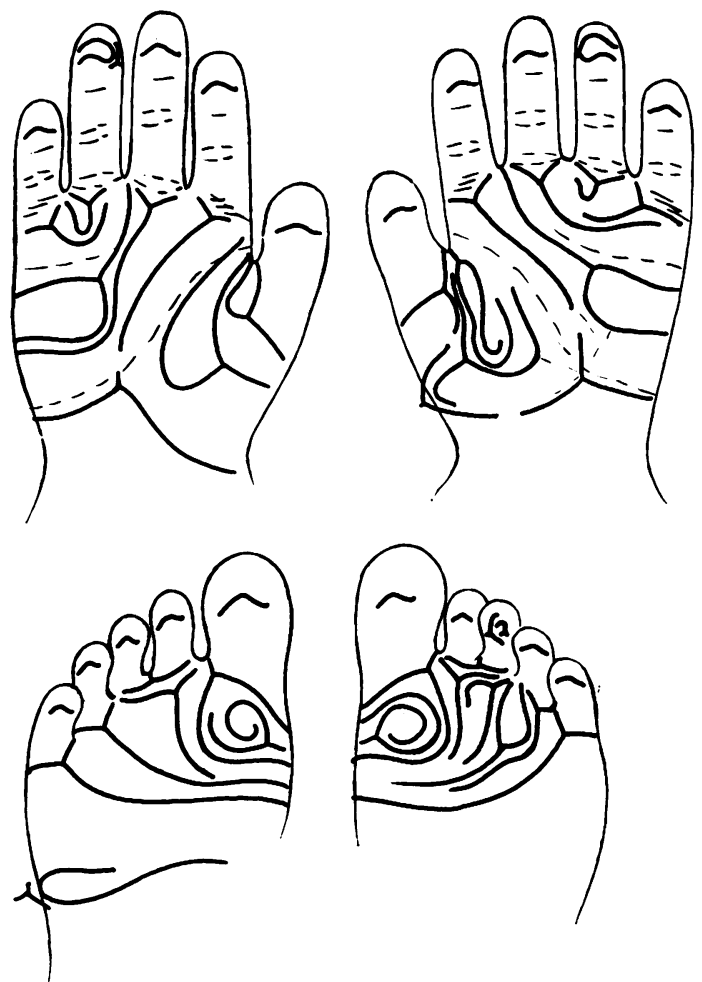

Fig. 3 Dermatoglyphic patterns of case 1 . on the proband's hands are abnormal. The finger print patterns, 8 arches and 2 ulnar loops, show a low intensity. The total finger ridge count, 20 ridges, is well below the mean figure of 145 ridges for English male controls. The pattern intensity on the palms is high; 5.0 loops per palm against 1.7 for males of the general population. On both palms there is a Sidney line, complete on the left hand and aberrant on the right hand. The axial triradius is on both hands distally placed $\left(t^{\prime \prime}\right)$. On the thenar/ first interdigital area of both hands there is a dislocation of the ridge arrangements, particularly on the right hand. The palmar configurations were not found in a sample of 980 English controls (450 males and 530 females).

On the soles, the toe patterns, 9 arches and 1 double loop, are of low intensity and are also unusual in normal people.

Case 2 (Fig. 4). The proband's dermatoglyphs show some features which are uncommon in normal people. White lines cutting across the epidermal ridges indiscriminately occur on fingers, palms, and soles of this case with extremely high frequency. This is a rare finding in young normal people as white lines tend to recede during adolescence and to reappear later in life. A pathological cause for the occurrence of white lines has been suggested by Cherrill (1950). He associated their presence with

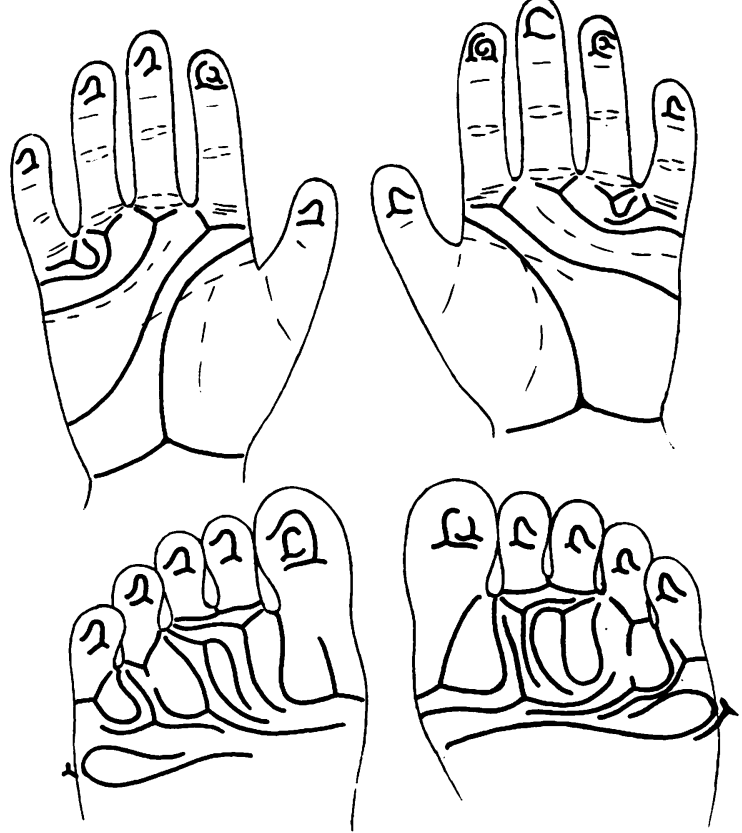

Fig. 4 Dermatoglyphic patterns of case 2 . 
disease or with a particular stage of a disease. The total finger ridge count, 180 ridges, is high, 35 ridges above the average for English male controls.

The plantar configurations show a high intensity, 5.0 loops per sole against 2.8 in males of the general population.

The pattern arrangements on the left sole occurred with a frequency of $2 / 550$ but those on the right were not found in the same sample of 550 controls ( 250 females and 300 males).

\section{CYTOGENETIC STUDIES}

Duplicate lymphocyte cultures were established on separate occasions from both cases. Only single cultures were set up from parents. Standard staining and trypsin-Leishman G-banded preparations were used routinely, with quinacrine Q-banding for markers where appropriate. Representative partial karyotypes are shown in Fig. 5.

Case 1. A deficiency of the short arm of a chromosome 7 was observed in all cells. G-banding showed an interstitial deletion of $7 p$ with breakpoints at bands $\mathrm{p} 13$ and $\mathrm{p} 21$. The deletion probably resulted in loss of material from both of these bands together with total loss of bands 14 and p15. The karyotyp was $46, \mathrm{XY}$, del(7)(pter $\rightarrow$ p21 ::p13 $\rightarrow$ qter).

Normal chromosomes were found in the parents apart from the presence of a centromeric variant in the mother whose karyotype was $46, X X, \operatorname{var}(\$)$ (cen,GTL 50,QFQ 55).

Case 2. Two abnormal chromosomes were con sistently present. One chromosome 7 showed $\bar{\Phi}$ major long arm deletion. Material deleted from the 7 was translocated to the end of the long arm of $Q$ chromosome 8. G-banding showed breaks at bands $7 \mathrm{q} 11$ and $7 \mathrm{q} 21$ with loss of a small part of the former and the greater part of the latter bands. The kary type was $46, X Y$,del(7)(q11q21),t(7;8)(7pter $\rightarrow 7 q 11 \frac{3}{3}$ $8 \mathrm{pter} \rightarrow 8 \mathrm{q} 24:: 7 \mathrm{q} 21 \rightarrow 7 \mathrm{qter}), 15 \mathrm{p}+, 22 \mathrm{ps}$ -

The chromosomes of both parents appeared to bs normal. Neither of the variants seen in the chromos somes of the proband could be detected in eithes parent.

\section{BLOOD GROUPS}

The probands and their parents were tested fop reactions with the $\mathrm{ABO}, \mathrm{MNSs}, \mathrm{P}, \mathrm{Rh}$, Lutheraid Kell, Lewis, Duffy, Kidd, Xg, and Colton systems The results were unremarkable (Table 1).

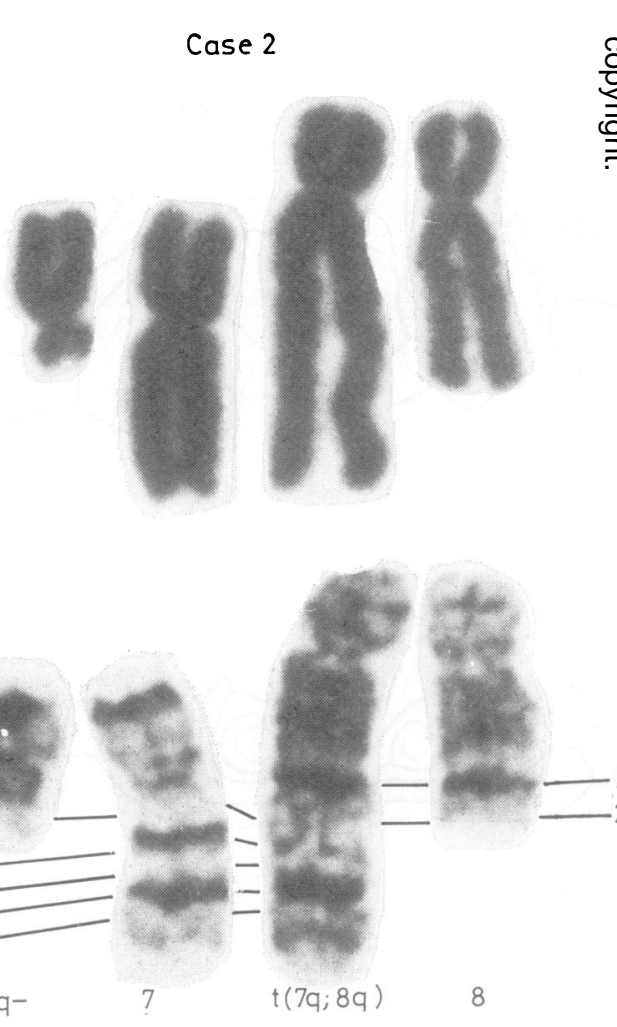

Fig. 5 Partial karyotypes of cases 1 and 2. 
Table 1 Blood group findings

\begin{tabular}{|c|c|c|c|c|c|c|c|c|c|c|c|c|c|c|c|c|c|c|c|}
\hline \multirow[t]{2}{*}{ Subject } & \multicolumn{19}{|c|}{ Blood group system } \\
\hline & $A B O$ & $M N$ & $S$ & $s$ & $P_{1}$ & $\boldsymbol{R h}$ & & $L u^{\mathbf{a}}$ & $\boldsymbol{K}$ & $\boldsymbol{k}$ & $L e^{a}$ & $L e^{b}$ & $F y^{\mathbf{a}}$ & $F y^{b}$ & $J k^{a}$ & $J k^{\mathbf{b}}$ & $X g{ }^{\star}$ & Coa & $\mathrm{Co}^{\mathrm{b}}$ \\
\hline Father of case 1 & $\mathbf{O}$ & $\mathbf{M N}$ & - & + & - & $\mathbf{R}_{1}$ & $\mathbf{R}_{1}$ & - & - & + & - & + & + & + & + & + & - & + & - \\
\hline Mother of case 1 & $\mathbf{A}_{1}$ & MN & + & + & + & $\mathbf{R}_{1}$ & $\mathbf{r}$ & - & - & + & + & - & - & + & + & + & + & + & - \\
\hline Case 1 & $\mathbf{A}_{1}$ & $\mathbf{M N}$ & - & + & + & $\mathbf{R}_{1}$ & $\mathbf{R}_{1}$ & - & - & + & + & - & - & + & + & - & - & + & - \\
\hline Father of case 2 & 0 & $\mathbf{M}$ & + & + & - & $\mathbf{R}_{1}$ & $\mathbf{r}$ & - & + & + & + & - & + & + & + & + & + & + & - \\
\hline Mother of case 2 & $\mathbf{O}$ & $\mathbf{M}$ & + & + & - & $\mathbf{R}_{1}$ & $\mathbf{r}$ & - & - & + & - & + & + & - & - & + & + & + & - \\
\hline Case 2 & $\mathbf{O}$ & $\mathbf{M}$ & + & - & - & $\mathbf{r}$ & $\mathbf{r}$ & - & - & + & - & + & + & - & - & + & + & + & - \\
\hline
\end{tabular}

\section{Discussion}

The principal clinical and cytogenetic findings in the cases reported here and in 20 previously reported cases of partial monosomy 7 are summarised in Table 2.

The two previously reported cases of short arm deletion (Wilson et al., 1973; Friedrich et al., 1975), along with the first of two cases of ring 7 (Zachai and Breg, 1973), were all mentally retarded and had craniostenosis. Other features present in two of these three cases include microcephaly, an antimongoloid palpebral slant, and ptosis. These observations permit the tentative recognition of a syndrome associated with $7 p$ deletion with the breakpoint at $7 \mathrm{p} 15$, and suggest that the ring 7 chromosome in the first case of Zachai and Breg (1973) must have had at least some of $7 \mathrm{p}$ distal to band 15 deleted, but that their second case, which differed phenotypically, must also differ cytogenetically. Our case 1 (case 5 of Table 2) also differs phenotypically in several respects, although he does have an antimongoloid palpebral slant, ptosis, and genital anomaly. Specifically he is not microcephalic and does not have craniostenosis. The differences in developmental abnormality are to be expected in view of his different deletion, involving interstitial loss of the short arm between breaks at p13 and p21. One may speculate that the limited features shared with the earlier cases, including the low total finger ridge count in common with the case of Friedrich et al. (1975), might be associated with the common loss of material between bands p13 and p15.

Among the long arm deletion cases three distinct groups can be recognised on cytogenetic grounds. The largest group have either a simple terminal deletion resulting from a single break at $7 \mathrm{q} 32$ or a similar loss secondary to a translocation. The six cases on which there are adequate clinical data (cases 7 to 12, inclusive, of Table 2) (de Grouchy et al., 1968, 1974; Harris et al., 1977; Kousseff et al., 1977) have in common mental retardation with microcephaly, low set or malformed ears, a bulbous nose, short stature, and genital anomaly. Two cases had diastasis recti, two had brachy- cephaly, and two had cleft lip and palate. The claim of Harris et al. (1977) that these features constitute a recognisable syndrome seems to be justified. The second group with long arm deletions comprises three cases with breaks at $7 \mathrm{q} 21$ and $7 \mathrm{q} 31$ or 32 (cases 15 to 17 of Table 2) (Ayraud et al., 1976; Higginson et al., 1976; Franceschini et al., 1978). They too show remarkably consistent clinical findings, namely mental retardation, retarded growth, ocular defects, bulbous nose, low set or malformed ears, congenital heart disease, and hypertonia, again strongly suggestive of a definable syndrome. The third group of long arm deletions is that with an interstitial deletion between breaks at $7 \mathrm{q} 11$ and $7 \mathrm{q} 21$ or 22 (cases 18 to 22 of Table 2, including our case 2 which is case 22 of the Table) (Valentine and Sergovich, 1977; Seabright and Lewis, 1978). This group is less easily defined clinically as two of the reported cases were mosaic and in one of those only $15 \%$ of cells were abnormal (Seabright and Lewis, 1978). Nevertheless, this group shows some phenotypic overlap with the second group. Two of the five cases have cardiac defect, two have downturned mouths, and one has low set ears. Two, including our case 2 , have epilepsy as do two cases in the second group. These similarities might be associated with a common loss of material around bands q21 or 22, but evidence from more cases will be needed before this can be regarded as anything more than hypothesis. Case 2 presented here is remarkable for the lack of morphological abnormality. In addition to being subnormal, he is epileptic as already mentioned. Apart from these features he has hypotonia like the patient of Valentine and Sergovich (1977) and also shares with their patient a high pattern intensity of the finger ridges. Cytogenetically he differs from the others in this group in deriving his deletion from a translocation with chromosome 8 . It may be that the phenotypic differences within this group depend on the precise position of the chromosome breaks giving rise to the deletion.

We are grateful to Dr Ruth Sanger and the staff of the MRC Blood Group Unit for undertaking the blood group determinations and to $\mathrm{Mr}$ Pedro Saldaña-Garcia for the dermatoglyphic analyses. 
Table 2 Features of the present and previously reported cases of partial monosomy 7

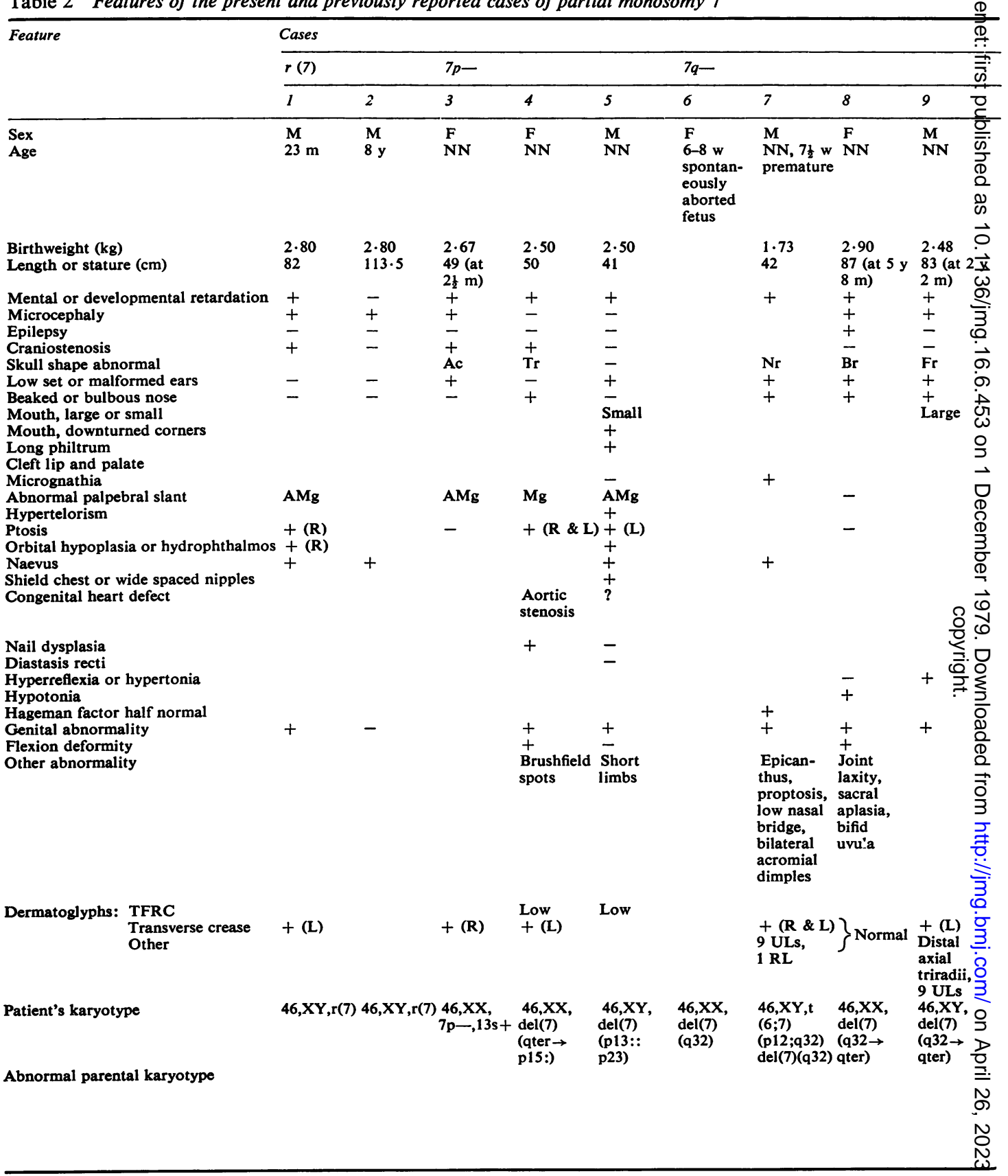

Cases. (1) Zachai and Breg (1973) case 1 ; (2) Zachai and Breg (1973) case 2; (3) Wilson et al. (1973); (4) Friedrich et al. (1975) case 1 ; (5) Present case 1 ; (6) Bass et al. (1973) case 2; (7) de Grouchy et al. (1968, 1974); (8) Harris et al. (1977) case 1; (9) Harris et al. (1977) case 2; (10) Harris et al. (1977) case 3; (11) Harris et al. (1977) case 4; (12) Kousseff et al. (1977); (13) Shokeir et al. (1973); (14) Friedrich et al. (1975) case 2, z Turleau et al. (1974); (15) Ayraud et al. (1976); (16) Higginson et al. (1976); (17) Franceschini et al. (1978); (18) Valentine and Sergovich (197); (19) Seabright and Lewis (1978) case 1 ; (20) Seabright and Lewis (1978) case 2; (21) Seabright and Lewis (1978) case 3 ; (22) Present case 2. 


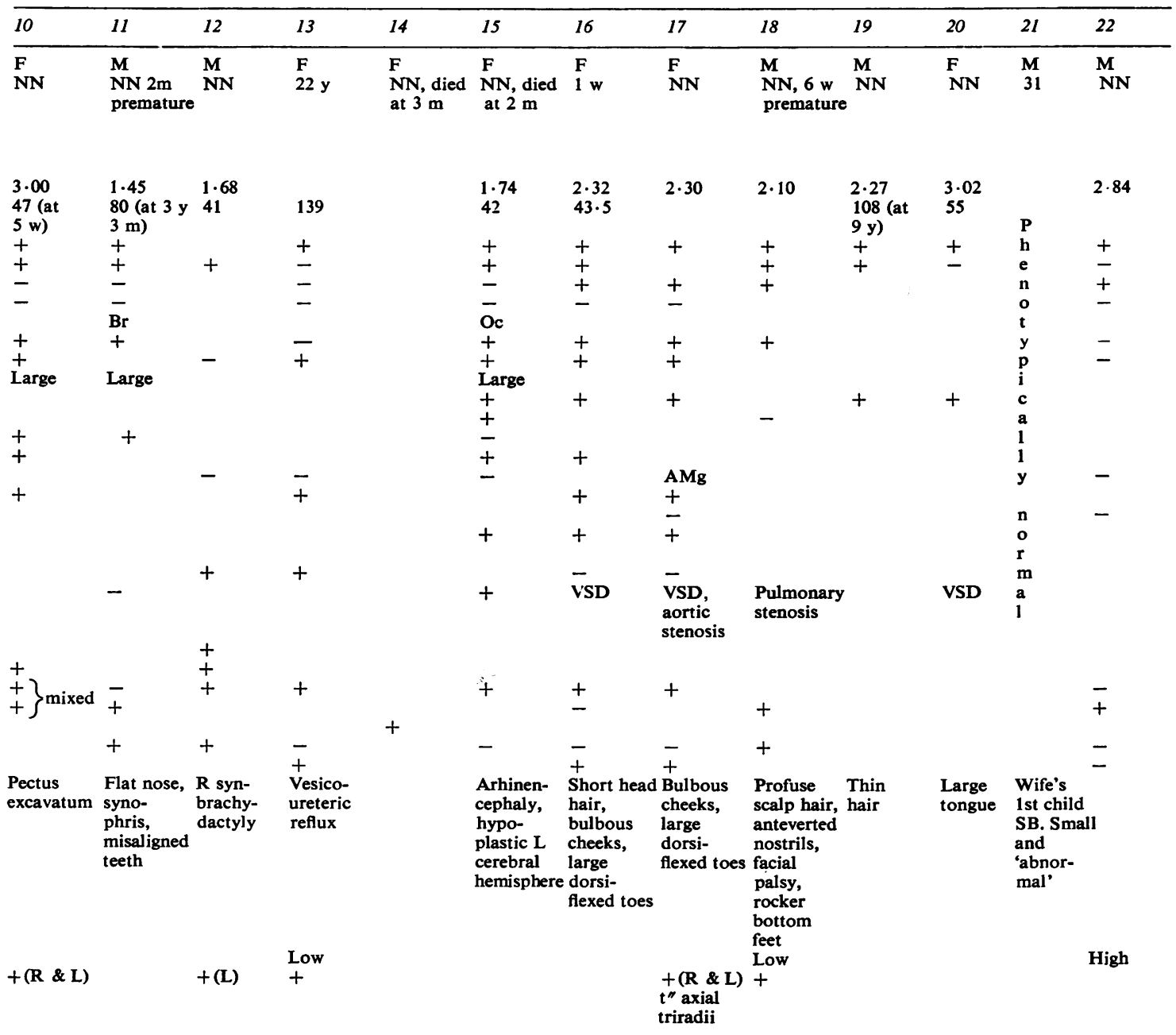

46,XX,del 46,XY,del 46,XY,del 46,XX, 46,XX,-7, 46,XX,del 46,XX,del, 46,XX,del 46,XY,del 46,XY,del 3:1 $1: 6 \quad 46, X Y$ $(7)(\mathrm{q} 32 \rightarrow(7)(\mathrm{q} 32 \rightarrow(7)(\mathrm{q} 32) \quad \mathrm{t}(2 \mathrm{p}-,, \quad+\operatorname{der}(7) \quad(7)(\mathrm{pter} \rightarrow(7)(\mathrm{pter} \rightarrow(7)(\mathrm{q} 21 ;$; $)(\mathrm{q} 11 \rightarrow(7)(\mathrm{q} 11:: \mathrm{mosaic}$ mosaic $\mathrm{t}(7 \mathrm{q} ; 8 \mathrm{q})$

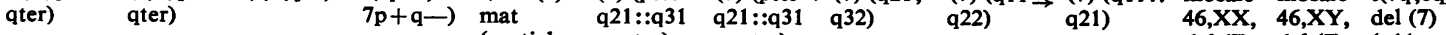
(partial $\rightarrow$ qter) $\rightarrow$ qter) $\quad$ del $(7)$ del (7) (q11:: monosomy $\quad$ (q11:: (q11:: q21) (7) $(\mathrm{q} 35:))$ $\mathrm{q} 21) / 46, \mathrm{q} 21) / 46$,

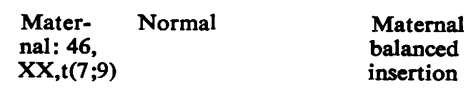

M, male; F, female; NN, neonate; Ac, acrocephaly; Tr, trigonocephaly; Nr, narrow cranium; Br, brachycephaly; Fr, frontal bossing with deep set eyes; Oc, prominent occiput; Amg, antimongoloid; Mg, mongoloid; VSD, ventricular septal defect; SB, stillbirth; UL, ulnar loop; RL, radial loop. 


\section{References}

Ayraud, N., Rovinski, J., Lambert, J. C., and Galiana, A. (1976). Délétion interstitielle du bras long d'un chromosome 7 chez une enfant lepréchaune. Annales de Génétique, 19, 265-268.

Bass, H. N., Crandall, B. F., and Marcy, S. M. (1973). Two different chromosome abnormalities resulting from a translocation carrier father. Journal of Pediatrics, 83, 1034-1038.

Cherrill, F. R. (1950). Finger prints and disease. Nature, 166, 581-584.

de Grouchy, J., Turleau, C., Josso, F., Gazengel, C., and Nedelec, J. (1974). Tentative localization of a Hageman (factor XII) locus on 7q, probably the $7 \mathrm{q} 35$ band. Human Genetics, 24, 197-200.

de Grouchy, J., Veslot, J., Bonnette, J., and Riodot, M. (1968). A case of ?6p- chromosomal aberration. American Journal of Diseases of Children, 115, 93-99.

de la Chapelle, A., Vuopio, P., Sanger, R., and Teesdale, P. (1976). The Colton blood groups in monosomy 7 of the bone marrow. Cytogenetics and Cell Genetics, 16, 280 283.

Franceschini, P., Silengo, M. C., Davi, G. F., Santoro, M. A., Prandi, G., and Fabris, C. (1978). Interstitial deletion of the long arm of chromosome 7: 46,XX,del(7) (pter $\rightarrow$ q2200::q3200 $\rightarrow$ qter). Human Genetics, 44, 345-348.

Friedrich, U., Lyngbye, T., and Øster, J. (1975). A girl with karyotype 46,XX,del(7) (qter $\rightarrow$ p15:). Humangenetik, 26, 161-165.

Harris, E. L., Wappner, R. S., Palmer, C. G., Hall, B., Dinno, N., Seashore, M. R., and Breg, W. R. (1977). $7 \mathrm{q}$ deletion syndrome (7q32 $\rightarrow 7 \mathrm{qter})$. Clinical Genetics, 12, 233-238.

Higginson, G., Weaver, D. D., Magenis, R. E., Prescott, G. H., Haag, C., and Hepburn, D. J. (1976). Interstitial deletion of the long arm of chromosome no. 7 (7q-) in an infant with multiple anomalies. Clinical Genetic, 10, 307-312.

Kousseff, R. G., Hsu, L. Y. F., Paciuc, S., and Hirschhor K. (1977). A partial long arm deletion of chromosome 7: 46,XY,del(7) (q32). Journal of Medical Genetics, 1 莆 $144-147$.

Rowley, J., and Potter D. (1976). Chromosomal bandirg patterns in acute non lymphocytic leukaemia. Blood, 705-721.

Ruutu, P., Ruutu, T., Vuopio, P., Kosunen, T. U., and de Chapelle, A. (1977). Defective chemotaxis in monosomyNature, 265, 146-147.

Seabright, M., and Lewis, G. M. (1978). Interstitial deletion of chromosome 7 detected in three unrelated patients Human Genetics, 42, 223-226.

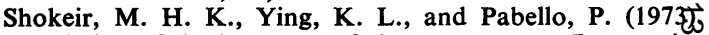
Deletion of the long arm of chromosome no. 7: tentatipe assignment of the Kidd (Jk) locus. Clinical Genetics, 360-368.

Turleau, C., de Grouchy, J., Chavin-Colin, F., Fouret, $\mathrm{M}_{\text {. }}$ Despres, P., and Hummel, M. (1974). Trisomie 9p: dew nouvelles observations. Annales de Génétique, 17, 167-179.

Valentine, H., and Sergovich, F. (1977). A syndrome assô ciated with interstitial deletion of chromosome 7q. Birfth Defects: Original Article Series, 13, No. 3B, 261-262. 을 Wilson, M. G., Fujimoto, A., Shinno, N. W., and Towner, J. W. (1973). Giant satellites or translocation? Cytogenetieg and Cell Genetics, 12, 209-214.

Zachai, E. H., and Breg, W. R. (1973). Ring chromosome्ठ with variable phenotypic expression. Cytogenetics and C Genetics, 12, 40-48.

Requests for reprints to Dr M. d'A. Crawfurd Kennedy-Galton Centre for Clinical Genefics Harperbury Hospital, Harper Lane, Radlett, Hettfordshire WD7 9HQ.

\section{Addendum}

Since submitting this paper for publication we have found a report by McPherson et al. (1976) that we had regrettably overlooked. They describe a boy with an interstitial deletion of band $7 \mathrm{p} 21$. This child had craniosynostosis as did other children reported with short arm 7 deletions distal to band $7 \mathrm{p} 15$, and this confirms the consistent loss of material in the
$7 \mathrm{p} 21-22$ region in 7 deletion cases with craniostenosis.

\section{Reference}

McPherson, E., Hall, J. G., Hickman, R., Gong, B. $\Phi$., Norwood, T. H., and Hoehn, H. (1976). Chromosome 7 short arm deletion and craniosynostosis. A 7-p syndrorme. Human Genetics, 35, 117-123. 